\title{
Tireoidite linfocítica canina em um Bull terrier
}

\author{
Canine lymphocytic thyroiditis in a Bull terrier \\ Regiani Nascimento Gagno Porto ${ }^{1}$, Veridiana Maria Brianezi Dignani de Moura ${ }^{1}$, Ana Paula Iglesias \\ Santin ${ }^{1}$, Carlos Eduardo Fonseca Alves ${ }^{2}$, Tatyane Penha Sales'2, Moema Pacheco Chediak Matos ${ }^{1}$, Marina \\ Pacheco Miguel $^{3}$ \& Luiz Augusto Batista Brito ${ }^{1}$
}

\begin{abstract}
RESUMO
A tireoidite linfocítica é uma enfermidade auto-imune e uma das principais afecções tireoidianas, responsáveis por causar hipotireoidismo primário em cães. O presente trabalho relata o caso de um canino, Bull terrier, macho, de dois anos de idade e histórico de morte súbita durante exercício em esteira. À macroscopia, as alterações relevantes compreenderam congestão e edema pulmonar e endocardiose de mitral. Ao exame microscópico foram verificadas endocardiose, aterosclerose em vasos de diversos órgãos e, na tireóide, constatou-se tireoidite linfocítica. O exame anatomopatológico compreendeu ferramenta decisiva na descrição das alterações e conclusão do diagnóstico, visto que não havia diagnóstico prévio da enfermidade.
\end{abstract}

Descritores: tireóide, cão, hipotireoidismo.

\section{ABSTRACT}

Lymphocytic thyroiditis is an autoimmune disease and the mean thyroidal lesion that usually results in canine primary hypothyroidism. This report describes a two years old male Bull terrier that died suddenly during exercise. Pulmonary congestion and edema as well as mitral endocardiosis were the macroscopic important finds. Microscopically were verified valvular endocardiosis, vessels with atherosclerosis and lymphocytic thyroiditis. How there was no previous diagnostic, the anatomopathologic exam was decisive to lesion descriptions and diagnostic conclusion.

Key words: thyroid, dog, hypothyroidism. 


\section{INTRODUÇÃO}

A tireoidite linfocítica é um distúrbio auto-imune, caracterizado por infiltrado difuso de linfócitos, plasmócitos e macrófagos no parênquima tireoidiano. Dentre os distúrbios que afetam a tireóide e causam disfunção na regulação hormonal da mesma, a tireoidite linfocítica é considerada a principal causa de hipotireoidismo primário $[6,9,12]$.

Há grande similaridade entre a tireoidite linfocítica canina e a tireoidite de Hashimoto em humanos, tendo características histológicas semelhantes, com ambas apresentado auto-anticorpos para tireoglobulina na corrente circulatória, reforçando a teoria de enfermidade auto-imune [4,8].

$\mathrm{Na}$ clínica de pequenos animais, equívocos em relação a diagnósticos dessa natureza são comuns, visto que a tireoidite linfocítica, muitas vezes, é diagnosticada clinicamente como hipotireoidismo, não sendo pesquisada e determinada a causa do mesmo. Desta forma, o presente relato tem o intuito de apresentar os principais achados clínicos e anatomopatológicos de um cão com tireoidite linfocítica, além de ressaltar a importância dos exames necroscópico e histopatológico no diagnóstico conclusivo dessa enfermidade tireoidiana.

\section{RELATO DE CASO}

Um canino, Bull terrier, macho, de dois anos de idade e histórico de morte súbita durante exercício em esteira, foi encaminhado ao Setor de Patologia Animal da Escola de Veterinária da Universidade Federal de Goiás, Goiânia, GO, para exame necroscópico e determinação da causa mortis. Não havia relato de doença prévia importante, exceto uma dermatite generalizada acompanhada de alopecia, sendo a mesma inicialmente tratada e não relacionada à endocrinopatia. $\mathrm{O}$ animal apresentava-se acima do peso e vinha sendo submetido à dieta balanceada e exercícios físicos regulares em esteira havia uma semana.

Ao exame necroscópico observaram-se edema pulmonar agudo e congestão, espessamento e irregularidade de pericárdio atrial bilateral, petéquias epicárdicas, endocardiose de mitral, congestão hepática e renal, assim como hemorragia pancreática difusa. Chamou a atenção o avantajado escore adiposo do cadáver. Fragmentos de coração, pulmão, linfonodos, SNC, fígado, rim, baço e tireóide foram colhidos, fixados em formol tamponado a $10 \%$, processados e incluídos em parafina, para a confecção de lâminas histológicas, sendo essas coradas com hematoxilina e eosina (HE).
Ao exame microscópico observaram-se congestão e hemorragia nos tecidos renal, pulmonar, hepático e pancreático, bem como necrose de células tubulares renais e edema pulmonar. No cérebro e cerebelo, a principal alteração foi a aterosclerose ou arteriosclerose lipídica (AL). No fígado havia degeneração microgoticular e necrose multifocal.

Degeneração mixomatosa mitral e subpericárdica (Figura 1A), de gânglio neural intramural e de fibras miocárdicas atriais, assim como edema intersticial e moderada aterosclerose da camada média arterial (Figura 1B), foram as alterações observadas no coração. À microscopia da tireóide foi evidenciada infiltração nodular multifocal de linfócitos, plasmócitos e macrófagos, além de congestão, destruição de folículos e colóide intersticial, caracterizando tireoidite linfocitária (Figuras 2A e 2B).

\section{DISCUSSÃO}

A obesidade e a dermatopatia constituíram os únicos e breves sinais de hipotireoidismo no animal em questão, o qual possivelmente originou-se a partir da tireoidite linfocítica diagnosticada no exame post mortem. Neste contexto, há informações na literatura de que o hipotireoidismo primário de cães freqüentemente resulta de alterações da própria tireóide, sendo a tireoidite linfocítica e a atrofia tireoidiana as causas mais comuns desta endocrinopatia $[1,5,10]$. Ainda, a doença é amplamente relatada em cães entre quatro e dez anos [6,10], diferentemente do observado, visto que o animal em questão tinha apenas dois anos.

Deficiências de hormônios tireoidianos interferem na atividade metabólica de diferentes órgãos e sistemas. Consequientemente, a sintomatologia é variável e inespecífica [10], como verificado neste caso, sendo que os sinais se instalam de forma sutil, gradual e podem passar despercebidos [11]. Assim, é provável que os sinais apresentados pelo animal, caracterizados por peso excedente e dermatite, não sugeriram prontamente hipotireoidismo associado ou não à doença tireoidiana primária, sendo os mesmos tratados individualmente e sem correlação com a endocrinopatia. Apesar disso, alguns autores referem que, dentre os achados mais relevantes, estão os distúrbios dermatológicos como seborréia, piodermite e alopecia $[7,10]$. Apontam ainda que os animais apresentam aumento de peso e, na maioria dos casos, os proprietários relatam que os mesmos apresentam-se ofegantes após exercícios físicos [7,10], o que não foi informado neste caso. 

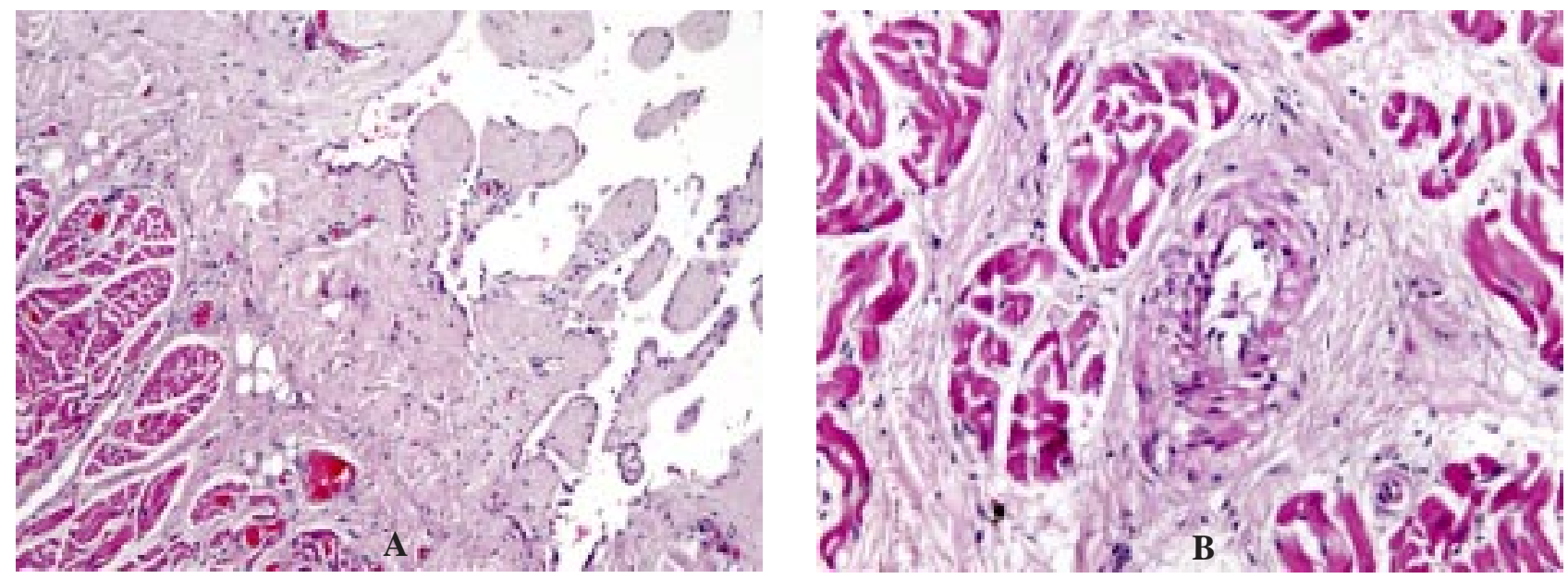

Figura 1. Fotomicrografia da tireoidite linfocítica em cão. A) Átrio. Degeneração mixomatosa pericárdica. HE, 100x. B) Coração. Artéria apresentando moderada vacuolização da camada média, caracterizando aterosclerose. HE, 200x.
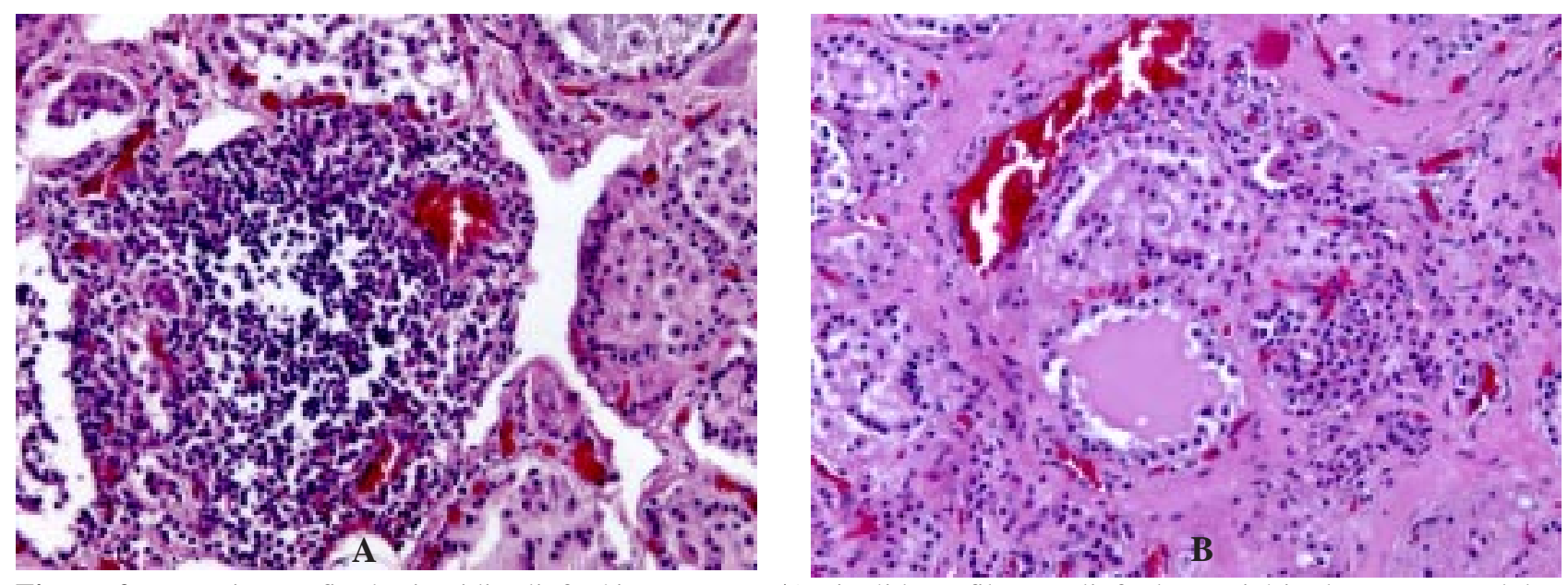

Figura 2. Fotomicrografia da tireoidite linfocítica em cão. A) Tireóide. Infiltração linfoplasmocitária de aspecto nodular. HE, 200x. B) Tireóide. Colóide intraluminal, intersticial e infiltrado linfoplasmocitóide. HE, 200x.

Ainda, cães hipotireóideos podem apresentar anormalidades no sistema cardiovascular [11]. Apesar de não haver referência de doença cardíaca ante mortem, foi constatada, macro e microscopicamente, degeneração mixomatosa de mitral, um achado comum em casos de tireoidite linfocítica [3,11]. Os achados microscópicos da tireóide e dos demais órgãos são semelhantes aos descritos em animais com tireoidite linfocítica, especialmente a aterosclerose $[2,4,12]$, que se apresentou de intensidade moderada na camada média das artérias.

Considerando as alterações histopatológicas encontradas nos estágios avançados da doença, a destruição folicular tireoidiana, devido à massiva infiltração leucocitária, compreende achado microscópico importante, com consequiente perda parenquimal e substituição por tecido conjuntivo [1,6,7]. Ressalta-se que a tireóide do Bull terrier deste relato apresentava infiltração linfocitária multifocal, com destruição folicular e extravasamento de colóide para o espaço intersticial, contudo, não foram observados sinais de fibrose, que pode ser justificado pela evolução da doença, a qual ainda não se apresentava em estágio avançado.

Possivelmente, o edema pulmonar agudo fatal desencadeou-se a partir de uma insuficiência cardíaca valvular latente, esta com origem na doença tireoidiana, que se tornou fulminante devido ao aumento da demanda cardíaca durante o treinamento na esteira. Ressalta-se que, em função da inespecificidade dos sinais e da evolução insidiosa, o hipotireoidismo primário, associado à tireoidite linfocítica, é inicialmente subestimado, sendo que somente exames laboratoriais específicos evidenciam esta importante endocrinopatia. Já quando o óbito advém na ausência de diagnóstico prévio da enfermidade, como ocorrera com o cão deste relato, o exame anatomopatológico torna-se ferramenta decisiva na descrição das alterações macro e microscópicas e na conclusão do diagnóstico. 


\section{REFERÊNCIAS}

1 Capen C.C. 2007. Endocrine glands. In: Maxie M.G. (Ed). Jubb, Kennedy, Palmer's Pathology of domestic animals. v.3. 5th edn. London: Elsevier, pp.325-428.

2 Dixon R.M., Reid S.W.J. \& Mooney C.T. 1999. Epidemiological, clinical, hematological and biochemical characteristics of canine hypothyroidism. Veterinary Record. 145: 481-487.

3 Feldman E.C. \& Nelson R.W. 2004. Hypothyroidism. In: Feldman E.C. \& Nelson R.W. (Eds). Canine and Feline Endocrinology and Reproduction. 3rd edn. Saint Louis: W.B. Saunders, pp.86-151.

4 Gosselin S.J., Capen C.C., Martin S.L. \& Krakowka S. 1982. Autoimmune lymphocytic thyroiditis in dogs. Veterinary Immunology and Immunopathology. 3: 185-201.

5 Graham P.A., Nachreiner R.F. \& Refsal K.R. 2001. Lymphocytic thyroiditis. Veterinary Clinics of North American Small Animal Practice. 31: 915-933.

6 Kemppainen R.J. \& Clark T.P. 1994. Etiopathogenesis of canine hypothyroidism. Veterinary Clinics of North American Small Animal Practice. 24: 467-76.

7 Kennedy L.J., Quarmby S., Happ G.M ., Barnes A., Ramsey I.K., Dixon R.M., Catchpole B., Rusbridge C., Graham P.A., Hillbertz N.S., Roethel C., Dodds W.J., Carmichael N.G. \& Ollier W.E.R. 2006. Association of canine hypothyroidism with a common major histocompatibility complex DLA class II allele. Tissue Antigens. 68: 82-86.

8 Nachreiner R.F., Refsal K.R., Graham P.A. \& Bowman M.M. 2002. Prevalence of serum thyroid hormone autoantibodies in dogs with clinical signs of hypothyroidism. Journal of the American Veterinary Medical Association. 220: 466-471.

9 Nachreiner R.F., Refsal K.R., Graham P.A., Hauptman J. \& Watson G.L. 1998. Prevalence of autoantibodies to thyroglobulins in dogs with nonthyroidal illness. American Journal of Veterinary Research. 59: 951-955.

10 Nelson R.W. 2001. Distúrbios endócrinos. In: Nelson R.W. \& Couto C.G. (Eds). Medicina interna de pequenos animais. 2.ed. Rio de Janeiro: Guanabara Koogan, pp.533-556.

11 Peterson M.E. \& Ferguson D.C. 1992. Moléstias da tireóide. In: Ettinger S.J. \& Feldman E.C. (Eds). Tratado de Medicina Interna Veterinária. 3.ed. São Paulo: Manole, pp.1706-1751.

12 Vajner L., Vortel V. \& Brejcha A. 1997. Lymphocytic thyroiditis in beagle dogs in a breeding colony: histological findings. Veterinary Medicine. 42: 333-338. 